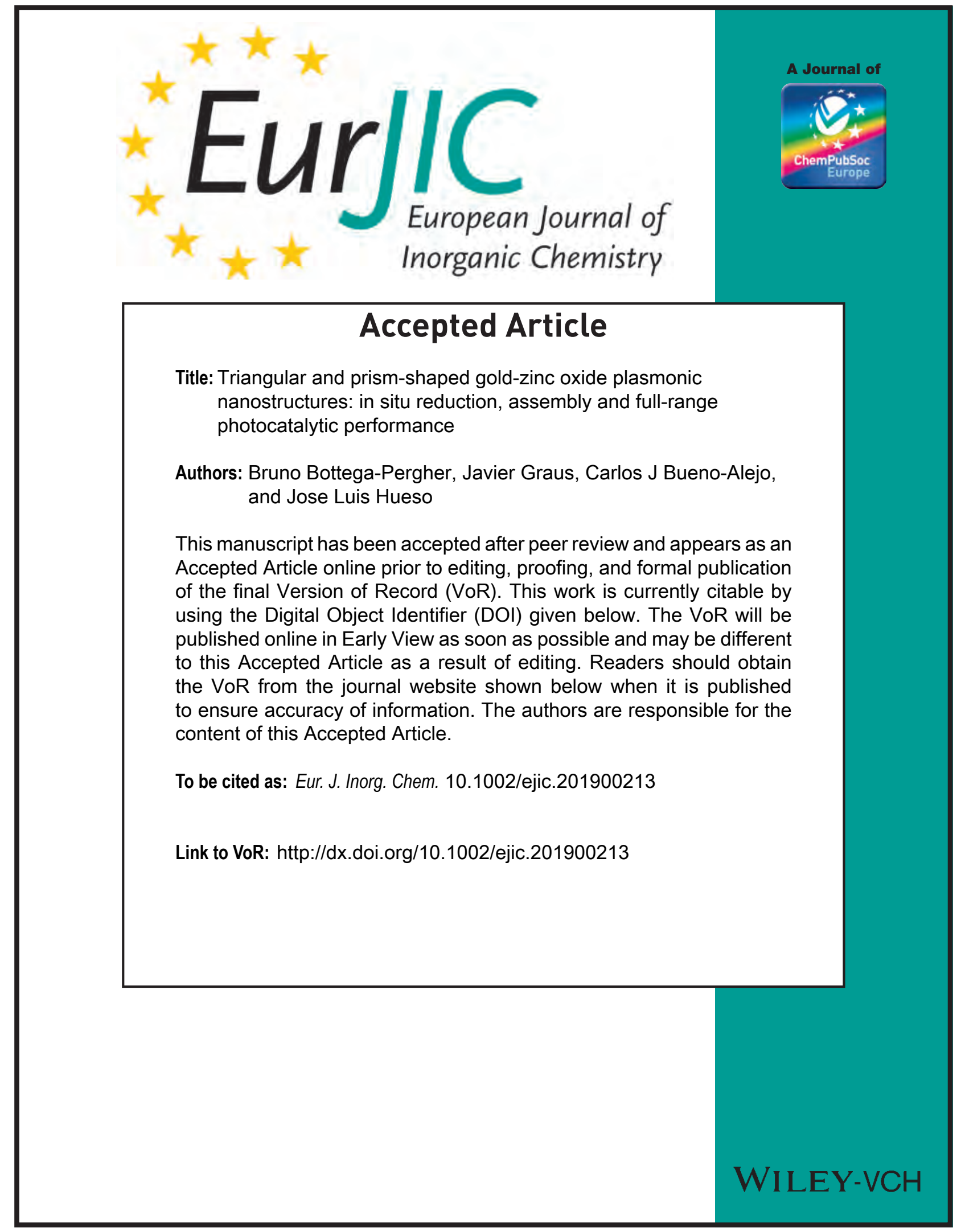




\title{
Triangular and prism-shaped gold-zinc oxide plasmonic nanostructures: in situ reduction, assembly and full-range photocatalytic performance
}

\author{
Bruno Bottega-Pergher, ${ }^{[a]}$ Javier Graus, ${ }^{[a]}$ Carlos J. Bueno-Alejo ${ }^{\star[a]}$ and Jose L. Hueso ${ }^{*[a],[b],[c]}$
}

\begin{abstract}
Gold-based nanocatalysts have been traditionally selected for multiple homogeneous and heterogeneous reactions of interest involving redox processes. Likewise, greener routes involving more efficient reactors and the use of inexpensive and nature-mimicking excitation sources have boosted the research on photocatalysts able to drive these chemical reactions upon excitation with multiple wavelength sources beyond the UV range. In the present work we report on a multi-step synthesis approach that implies the in situ generation of triangular and prism-shaped gold nanostructures with a localized surface plasmon resonance effect and their direct assembly onto a $\mathrm{ZnO}$ nanostructured semiconductor support. Different LED excitation sources in the whole UV-Vis-NIR range have been systematically selected to activate these hybrid materials in the selective reduction of p-nitrophenol (4-NP), a wellknown contaminant by-product. While $\mathrm{ZnO}$ becomes preferentially active in the UV window, the anisotropic shape of these gold plasmonic nanostructures helps to broaden the photocatalytic response of $\mathrm{ZnO}$ towards the visible and NIR range, being especially active under $460 \mathrm{~nm}$ blue light irradiation and expanding their potential application in multiple solar-driven catalytic processes of interest for decontamination and upgrading of toxic chemicals.
\end{abstract}

\section{Introduction}

The transformation of phenolic compounds into addedvalue chemicals of interest is a matter of great research interest. Many of these substrates exhibit harmful effects on the blood, liver and central nervous system ${ }^{[1]}$. These compounds are commonly found in industrial processes and agricultural waste water $^{[1]}$, being generally treated with advanced oxidation

[a] Mr. B. Bottega-Pergher, Mr. J. Graus, Dr. C.J. Bueno-Alejo*, Dr. J.L. Hueso*

Department of Chemical and Environmental Engineering (IQTMA) and Institute of Nanoscience of Aragon (INA)

University of Zaragoza, Spain

Campus Rio Ebro, R+D Building, C/Poeta M. Esquillor, s/n

E-mail: jlhueso@unizar.es / carlosb@unizar.es

Homepage: http://www.unizar.es/nfp/nfp.php?s=10

[b] Dr. J.L. Hueso*

Networking Research Center on Bioengineering, Biomaterials and Nanomedicine (CIBER-BBN), 28029 Madrid, Spain

[c] Dr. J.L. Hueso*

Instituto de Ciencia de Materiales de Aragon (ICMA), Consejo

Superior de Investigaciones Científicas (CSIC-U.Zaragoza) methods like photo-Fenton degradation, ozonation and/or electrochemical oxidation ${ }^{[2]}$. The most widespread approaches can exhibit certain limitations such as narrow working range of $\mathrm{pH}$ and deactivation by phosphate anions ${ }^{[2]}$. In this regard, photocatalysis appears as an affordable and promising alternative to overcome these limitations, not only acting as an effective technology to remediate pollutants that are detrimental for human health, but also as a precise and selective tool for manufacturing valuable compounds such as antipyretics or analgesics ${ }^{[3]}$.

Photocatalysts devoted to the liquid phase reactions, are typically assisted by an external light source to oxidize or reduce species. In many cases, these reactions are carried out with the aid of other co-reactants such as hydrogen peroxide or sodium borohydride with moderate to strong oxidant or reducing power, respectively ${ }^{[4-6]}$. The most reported photocatalytic material are semiconductors like titanium dioxide $\left(\mathrm{TiO}_{2}\right)$ or zinc oxide ( $\mathrm{ZnO})$, since they show relatively low price, great performance, chemical stability and long durability ${ }^{[3,}$ 4, 7-19]. However, their major downside is the specific requirement of ultraviolet (UV) wavelengths for their photoactivation, which is relatively more expensive to maintain and represents only around $5 \%$ of the total solar radiation. In this context, efforts are being made to produce high-performance photocatalysts which can successfully perform in the visible to near-infrared range that would account for ca. $40 \%$ and $55 \%$ of the solar radiation, respectively ${ }^{[20]}$.

Nanotechnology enters in this context to provide photocatalysts with metallic nanostructures that exhibit the socalled localized surface plasmon resonance effect (LSPR). This effect represents an excellent example on how properties on metallic materials can be strongly affected in the nanoscale. Silver or gold-based nanoparticles can enhance the catalytic response of other material upon excitation with visible-near infrared (Vis-NIR) light due to this LSPR effect. By using these materials, it is feasible to promote the reactions under milder conditions and without harmful agents ${ }^{[3,10-18,21,22]}$. 
The different shapes and sizes of plasmonic nanoparticles give rise to distinct plasmon absorption bands in the visible and/or NIR range ${ }^{[13,14,16,23-29]}$. Particles which possess edges, like triangles, exhibit highly localized charge accumulation events and larger reactivity when compared to spherical ones of the same average size ${ }^{[28-32]}$. This work focuses on the synthesis and thorough evaluation of the photocatalytic response of gold nanotriangles and nanoprisms in situ generated and deposited onto zinc oxide on the basis of its wellknown photocatalytic response as semiconductor material. Remarkably, the presence of these plasmonic gold nanostructures promotes the selective hydrogenation of $p$ nitrophenol (4-NP) into p-aminophenol (4-AP) upon illumination with different LEDs emitting in the visible and NIR ranges, being more efficient in the presence of a blue-emitting wavelength of $460 \mathrm{~nm}$. As a result, the photocatalytic action of the $\mathrm{ZnO}$ nanostructured support (that is preferentially active in the UV region) is expanded towards higher excitation wavelengths, thereby paving the way for solar driven applications of this hybrid plasmonic photocatalyst.

\section{Results and Discussion}

\section{Synthesis of the anisotropic Au-ZnO nanohybrids}

The synthesis of the Au-ZnO consisted in an in-situ reductiondeposition method $^{[33]}$ that included the use of sodium citrate as ligand stabilizer, sodium borohydride as reducing agent and sodium hydroxide to promote a highly alkaline reaction conditions $(\mathrm{pH} \sim$ 12.5). This basic ambient with a high concentration of hydroxyl groups has been previously demonstrated to favor the preferential formation of anisotropic gold nanostructures ${ }^{[33,34]}$. A simplified overview of the synthesis approach is displayed below (Figure 1, specific experimental details are described in the Experimental Section). An overall $\mathrm{Au}$ wt $\%$ loading close to $1 \%$ was achieved according to MP-AES analysis.

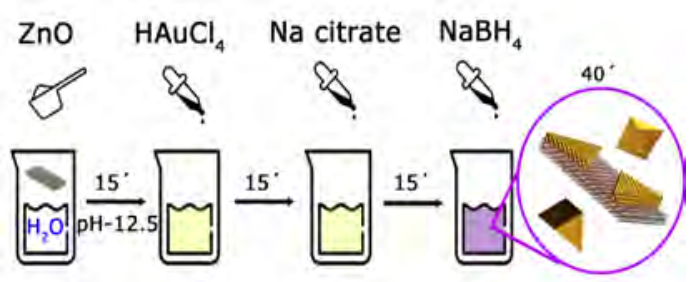

Figure 1. Simplified scheme of the reduction-precipitation steps carried out to yield anisotropic Au-ZnO nanohybrids (see Experimental for further details).
Figure $2 \mathrm{a}$ shows the XRD patterns corresponding to the $\mathrm{ZnO}$ and Au-ZnO nanoparticles, respectively. ZnO exhibits a hexagonal phase with a wurtzite type structure (space group $\mathrm{P} 63 \mathrm{mc}$ ) and the presence of gold with a cubic structure (space group $\mathrm{Fm}-3 \mathrm{~m}$ ) is confirmed by the presence of the diffraction peak at $38.2^{\circ}$ corresponding to the (111) orientation plane. The UV-Vis-NIR spectra displayed in Figure $2 b$ evidenced a clear modification in the absorption spectrum of $\mathrm{ZnO}$, a semiconductor with an energy band-gap located in the UV region, when Au was present. The deployment of the gold nanostructure led to a redshift of the maximum absorption band and a broadening of the band throughout the whole visible to NIR range. This redshift is very common for anisotropic shaped gold nanostructures with a localized surface plasmon resonance effect (LSPR). It normally expands the maximum absorption band beyond the typical values of $530 \mathrm{~nm}$ detected for nanospheres with sizes $\sim 15-40 \mathrm{~nm}^{[35]}$. In our case, probably due to the small size of the gold nanoparticles, this value is around $590 \mathrm{~nm}$.
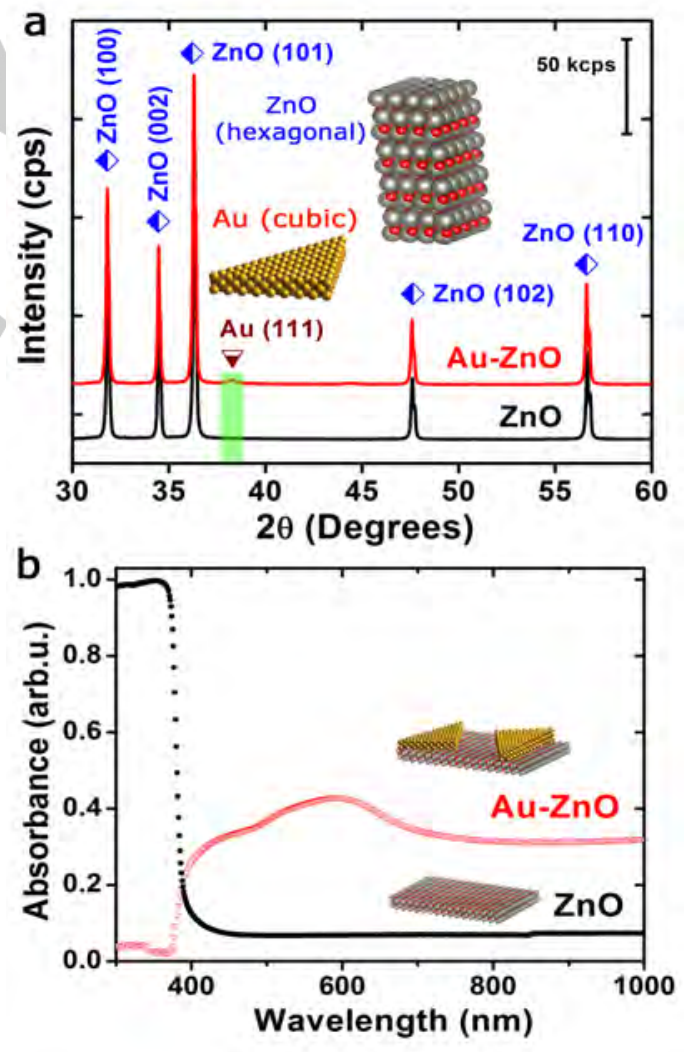

Figure 2. a) XRD patterns for the $\mathrm{ZnO}$ and $\mathrm{Au}-\mathrm{ZnO}$ nanoparticles and their corresponding crystallographic assignations attributable to a hexagonal phase for $\mathrm{ZnO}$ and a cubic phase for Au, respectively.; b) UV-Vis-NIR spectra corresponding to the $\mathrm{ZnO}$ (black dotted symbols) and the $\mathrm{Au} / \mathrm{ZnO}$ nanoparticles (red triangles symbols), respectively. 
Transmission Electron Microscopy (TEM) analysis of the collected powdered catalyst corroborated the successful and preferential formation of anisotropic Au NPs with triangular (Figure 3a-3b) (60\% yield), prism (Figure 3c-3e), pyramidal/rhombohedral (Figure $3 f$ ) and dome-like shapes (40\% yield for the remaining shapes) (Figure $3 d$ and Figure S1). Analysis of multiple lattice distances confirmed the hexagonal phase of ZnO and the cubic phase of the gold nanoparticles (Figure 3 and Figure S2). Furthermore, an excellent assembly with the $\mathrm{ZnO}$ nanoparticles acting as semiconductor support was also observed. Average sizes of $\sim 25-30 \mathrm{~nm}$ with certain polydispersity were obtained after inspection of more than 100 individual nanoparticles (see also Figure S1).
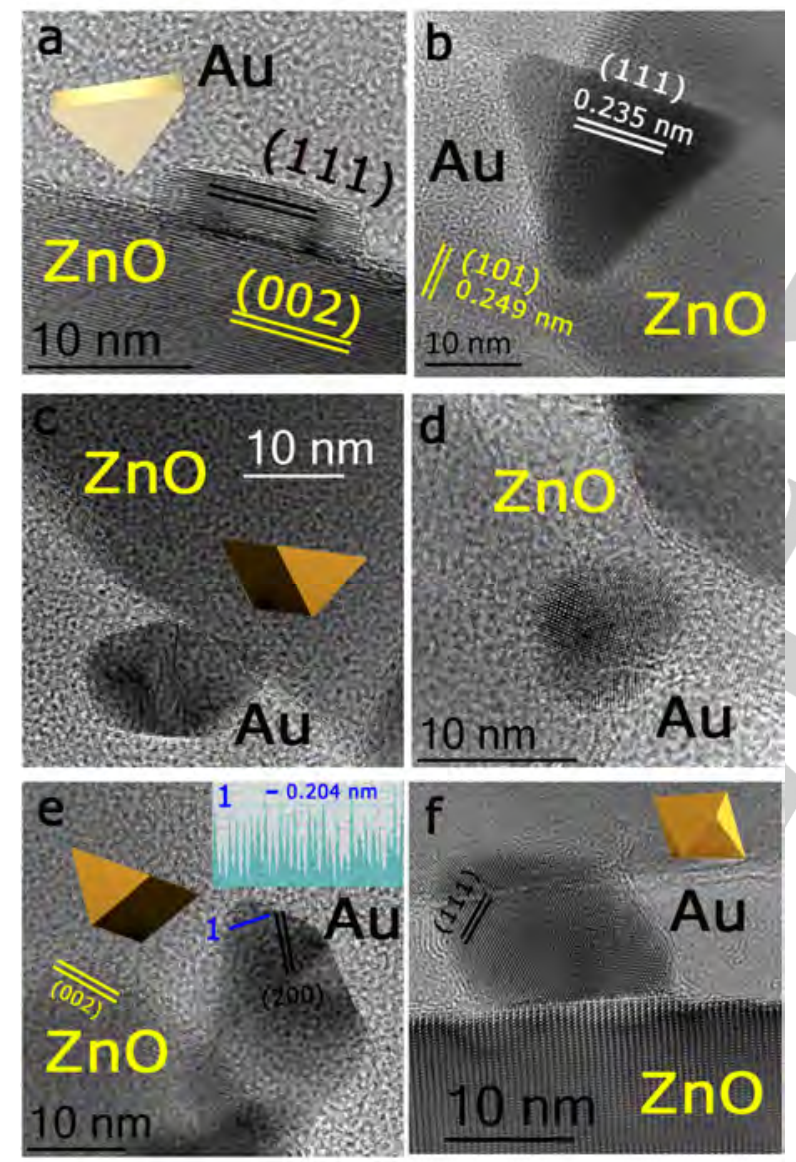

Figure 3. Representative HR-TEM images of the Au-ZnO photocatalyst and the different shapes identified for the $\mathrm{Au}$ nanoparticles: a) and b) Nanotriangles $(60 \%)$; c) to e) prism and dome-like nanostructures $(20 \%) ;$ f) pyramidal or rhombohedral nanoshapes (20\%); Insets with 3-D models are included in some cases for clarity. Lattice distances indexation have been obtained from the analysis of Filtered Fourier Transform patterns and corroborated the hexagonal phase of $\mathrm{ZnO}$ and the cubic phase of Au NPs (see also Figure $\mathrm{S} 2$ in the Supporting Information). Inset in e correspond to average atomic distances along the profile labelled as 1.
Previous studies have suggested the strong influence of $\mathrm{pH}$ as a key control parameter to increase the yield of anisotropic gold nanostructures ${ }^{[33,36]}$. This influence has been further confirmed and extended in this study that enabled us to generate triangular-shape Au structures despite of using ZnO instead of an accommodating support with a more basic nature (i.e. hydrotalcites) ${ }^{[4,33]}$. In addition, a control experiment carried out at neutral $\mathrm{pH}$ rendered the preferential formation of pseudospherical Au NPs (see Figure S3), thereby confirming the influence of basic $\mathrm{pH}$ to favor the preferential growth of gold anisotropic shapes.

\section{Photo-assisted reduction of p-nitrophenol}

The selective hydrogenation of 4-nitrophenol (4-NP) into 4aminophenol (Figure 4c) was carried out in an experimental setup displayed in Figure 4a-4b (see Experimental Section for further details). To differentiate the specific photocatalytic enhancement provided by the presence of plasmonic gold, a set of different LEDs with specific excitation wavelengths was selected. LEDs scanning the UV range $\left(\lambda_{\mathrm{exc}}=365 \mathrm{~nm}\right)$, visible range (blue- $\lambda_{\text {exc }}=460 \mathrm{~nm}$ and orange- $\lambda_{\text {exc }}=590 \mathrm{~nm}$, Figure 4a$4 b)$ and the near-infrared window $\left(\lambda_{\text {exc }}=850 \mathrm{~nm}\right)$ were tested individually both for $\mathrm{ZnO}$ and Au/ZnO photocatalysts, respectively. Control experiments were additionally carried out in the absence of catalyst (photolysis) and in the absence of LED irradiation (dark conditions).

The LED-assisted hydrogenation of 4-NP into 4-AP in the presence of sodium borohydride $\left(\mathrm{NaBH}_{4}\right)$ (Figure $4 \mathrm{c}$ ) was monitored by UV-Vis spectroscopy through the evolution of its absorption band at $400 \mathrm{~nm}$ (in the form of the p-nitrophenolate ion), that is progressively reduced to $p$-aminophenol with the concomitant formation of a new band at $300 \mathrm{~nm}$ if the reaction is successful (see Figure $4 d)^{[33,37,38]}$. The reaction was assumed to follow a pseudo-first kinetic order due to the excess of both catalyst and $\mathrm{NaBH}_{4}$, and an apparent kinetic constant could be estimated $^{[38,39]}$.

The comparative photocatalytic performance of the $\mathrm{ZnO}$ and Au/ZnO nanohybrids under selected LED irradiation wavelengths has been displayed in Figure 5 and summarized in Table 1 for all the explored conditions including control experiments. The photo-induced conversion profile of the catalysts was calculated as the number of mols of 4-NP hydrogenated at a time $t$ per mols of $4-N P$ when $t=0 \mathrm{~min}^{[38]}$ (see 
Figures $5 \mathrm{a}-5 \mathrm{c}$ and Table 1). Likewise, since the concentration of $\mathrm{NaBH}_{4}$ was in great excess and considered as approximately constant throughout the reaction, the hydrogenation rate was approximated by a pseudo-first kinetic order regarding the 4-NP concentration. Figures $5 \mathrm{~d}$-ef show the plot of $\operatorname{Ln}[C(t) / C(0)]$ against reaction time, being $C(t)$ and $C(0)$ the concentrations of 4-NP after LED irradiation time, $t$ and $t=0$, respectively. From linear fittings based on this pseudo-first order kinetics, an apparent kinetic constant ( $k_{\text {app }}$, Table 1$)$ was determined for both pure $\mathrm{ZnO}$ and $\mathrm{Au}-\mathrm{ZnO}$ photocatalysts under different experimental conditions (Figure 5 and Table 1).
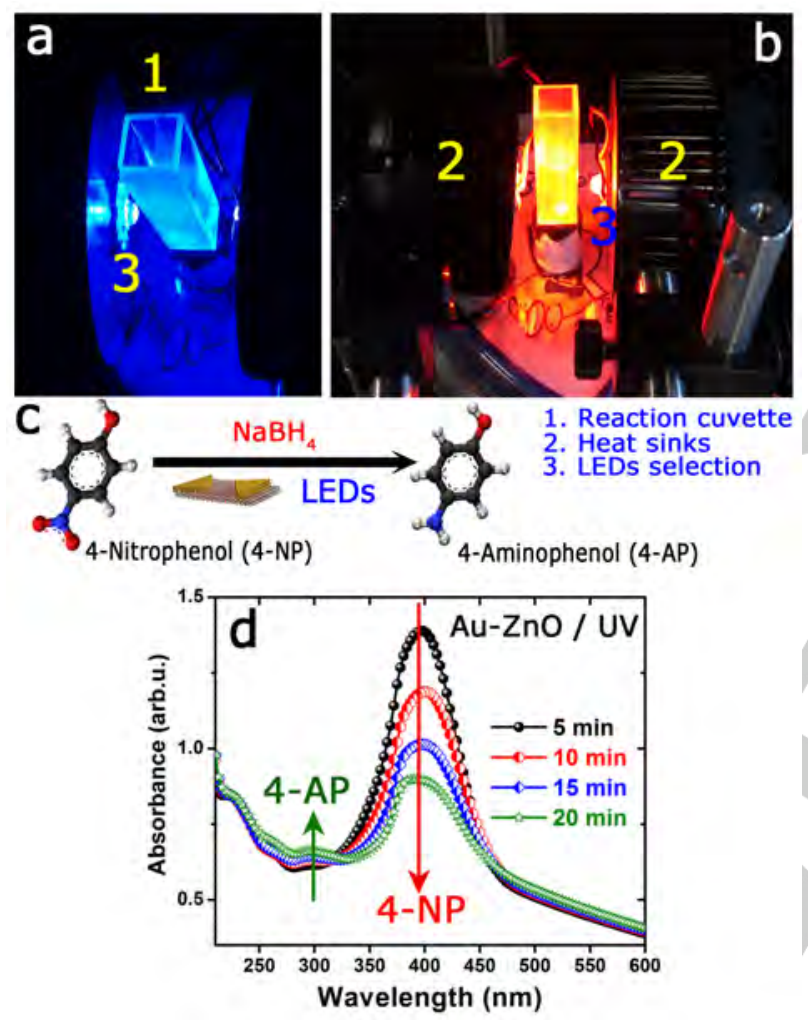

Figure 4. Digital images of the LED irradiation setup to perform the photoactivated hydrogenation of 4-NP: a) experimental setup using a set of two blue-LEDs $\left(\lambda_{\mathrm{exc}}=460 \mathrm{~nm}\right)$; b) experimental setup using a set of two orangeLEDs $\left(\lambda_{\mathrm{exc}}=590 \mathrm{~nm}\right)$; Numbers in $\left.\mathrm{a}\right)$ and $b$ ) refer to the main components of the LED irradiation setup: 1 . Quartz reaction cuvette for the reactants and catalysts that includes a magnetic stirrer; 2 . Sink devices to support the LED lamps and remove heat; 3 . Selection of different high radiance LED lamps (from UV to NIR ranges) to illuminate the cuvette from opposite sides; Please note that an additional fan is also placed in front of the cuvette to avoid overheating issues of the system; c) Scheme of the test reaction; d) UV-Vis spectra of the evolution in a typical photocatalytic reaction. This evolution over time corresponds to an experiment carried out with the Au-ZnO photocatalyst upon irradiation with the UV-LED at $365 \mathrm{~nm}$.
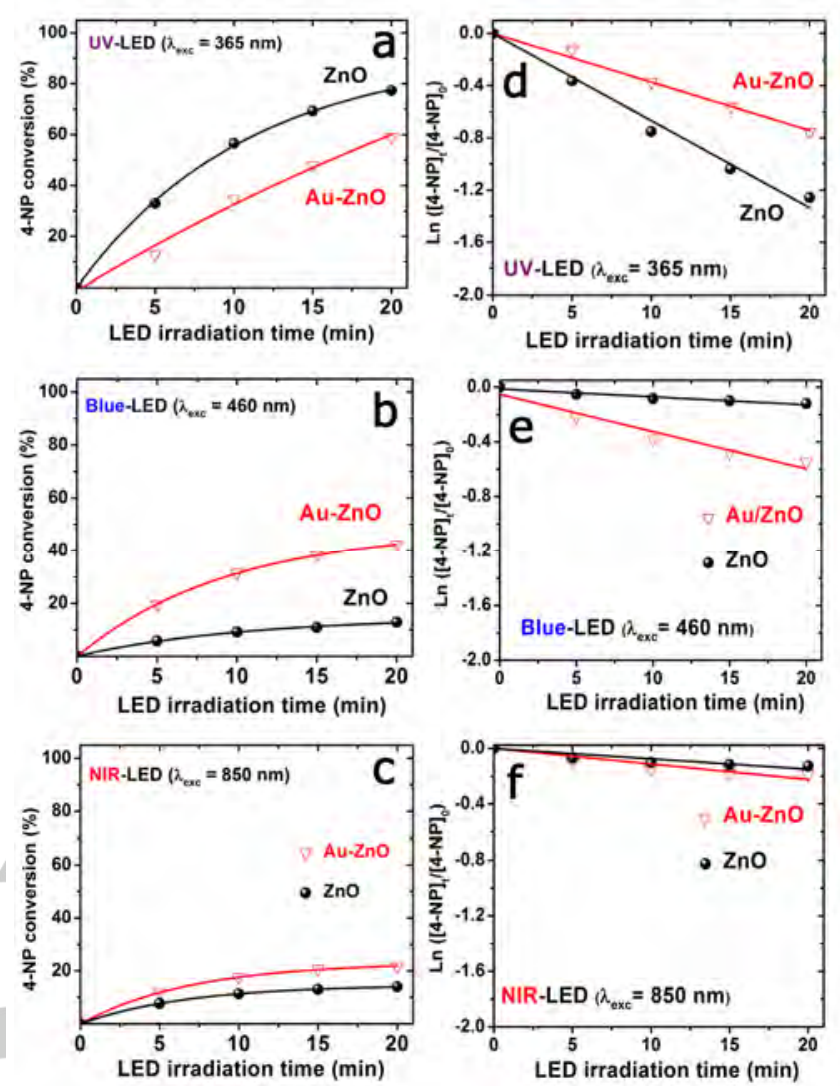

Figure 5. Catalytic performance of $\mathrm{ZnO}$ and $\mathrm{Au}-\mathrm{ZnO}$ photocatalyst under different LED irradiation wavelengths: a)-b)-c) 4-NP conversion against different irradiation times, using UV $\left(\lambda_{\text {exc }}=365 \mathrm{~nm}\right)$, Blue $\left(\lambda_{\mathrm{exc}}=460 \mathrm{~nm}\right)$ and $\operatorname{NIR}\left(\lambda_{\text {exc }}=850 \mathrm{~nm}\right)$ LEDs, respectively; d)-e)-f) plots of Ln([NP $\left.]_{\mathrm{t}}[\mathrm{NP}]_{0}\right)$ against irradiation times, being $[N P]_{t}$ and $[N P]_{0}$ the concentration of $4-N P$ at time $t$ and $\mathrm{t}=0$, respectively.

The photocatalytic tests carried out under UV-LED irradiation rendered the maximum 4-NP conversion levels (Figure 5a and Table 1). At this particular LED wavelength $\left(\lambda_{\mathrm{exc}}=365 \mathrm{~nm}\right)$, the presence of gold could be considered detrimental for the photoresponse of the ZnO pure nanoparticles or the direct LED action in the absence of any catalyst (i.e. photolysis, Table 1). Au nanostructures seem to be competitively absorbing energy and interfering in the photolysis events. In contrast, under blue-LED irradiation conditions $\left(\lambda_{\mathrm{exc}}=460 \mathrm{~nm}\right.$ ), no photolysis events were encountered (Table 1) and the Au-ZnO clearly outperformed its $\mathrm{ZnO}$ counterpart with higher 4-NP conversion levels and higher $k_{\text {app }}$ values (Figure $5 b-5 e$ and Table 1 ). Under blue light, the electrons on the gold particles seem to be responsible for the photocatalytic effect. The reason for this improvement has been tentatively attributed to the effect of interband electronic transition in the gold nanoparticles/triangles ${ }^{[40]}$. Once the gold 
electrons are excited by the blue light, probably not all of them can overcome the energy barrier to be transferred to the support material, ZnO, thereby staying on the gold's surface until they can be directly used for the reduction reaction of the 4-NP. Another contribution to the better performance of the catalyst at this wavelength could arise from the formation of complexes between the catalyst and the phenolic compound.

Table 1. Kinetic values for the reactions with $\mathrm{Au} / \mathrm{ZnO}, \mathrm{ZnO}$ and no catalyst (blank) under irradiation with different LEDs.

\begin{tabular}{|c|c|c|c|c|}
\hline $\begin{array}{l}\text { Irradiation } \\
\text { conditions }\end{array}$ & $\begin{array}{l}\text { Reaction and Kinetic } \\
\text { Parameters }\end{array}$ & $\begin{array}{l}\text { No } \\
\text { catalyst }\end{array}$ & ZnO & $\mathrm{Au} / \mathrm{ZnO}$ \\
\hline $\begin{array}{c}\text { Dark } \\
\text { (No LEDs) }\end{array}$ & $\begin{array}{l}\text { Hydrogenation rate }{ }^{[\mathrm{a}]} \\
k_{\mathrm{app}}^{[\mathrm{b}]} \\
\text { 4-NP Conversion (\%) }\end{array}$ & $\begin{array}{l}\text { N.D. } .^{[d]} \\
\text { N.D. } \\
\text { N.D. }\end{array}$ & $\begin{array}{c}6.4 \\
9.7 \\
22.0\end{array}$ & $\begin{array}{l}0.0 \\
0.2 \\
0.4\end{array}$ \\
\hline & Hydrogenation rate & N.D. & 6.1 & 9.2 \\
\hline $\begin{array}{l}\text { LED-NIR } \\
(\lambda=850 \mathrm{~nm})\end{array}$ & $\begin{array}{c}k_{\text {app }} \\
\text { 4-NP Conversion (\%) }\end{array}$ & $\begin{array}{l}\text { N.D. } \\
\text { N.D. }\end{array}$ & $\begin{array}{c}6.0 \\
14.0\end{array}$ & $\begin{array}{c}9.1 \\
21.7\end{array}$ \\
\hline
\end{tabular}

\begin{tabular}{ccccc} 
LED- & Hydrogenation rate & N.D. & 4.3 & 8.1 \\
Orange & $k_{\text {app }}$ & N.D. & 4.7 & 8.2 \\
$(\lambda=590 \mathrm{~nm})$ & 4-NP Conversion (\%) & N.D. & 10.8 & 17.4 \\
& & & & \\
& & & \\
LED-Blue & Hydrogenation rate & N.D. & 4.0 & 15.4 \\
$(\lambda=460 \mathrm{~nm})$ & $k_{\text {app }}$ & 1.6 & 5.8 & 27.3 \\
& 4-NP Conversion (\%) & 3.0 & 11.9 & 42.3 \\
& & & & \\
& & & & 10.2 \\
LED-UV & Hydrogenation rate & - & 26.0 & 39.0 \\
$(\lambda=365 \mathrm{~nm})$ & $k_{\text {app }}$ & 105 & 63.9 & 59.0 \\
& 4-NP Conversion (\%) & 87.6 & 77.4 & \\
\hline
\end{tabular}

[a] Hydrogenation rate expressed in umols of hydrogenated 4-NP per mg and per min (cumulative values after 5 min of LED irradiation); ${ }^{[b]}$ Apparent kinetic constant assuming a pseudo-first reaction order $\left(\mathrm{min}^{-1} \times 10^{3}\right)$; ${ }^{[c]}$ conversion expressed in terms of mols of 4-NP hydrogenated after $20 \mathrm{~min}$ irradiation per mols of 4-NP at $t=0 \mathrm{~min} ;{ }^{[\mathrm{d}]}$ Non-Detectable reaction evolution.

As previously reported in literature, these complexes may expand the typical absorption of the semiconductor to the visible range so they could become photoactive at $460 \mathrm{~nm}^{[12]}$. Although unlikely, this latter contribution can not completely ruled out. Under UV light, however, the gold particles seemed to capture the energy that could otherwise be used for photolysis, which showed to be the most significant effect among the Au-ZnO, $\mathrm{ZnO}$ and blank samples, being the one without catalyst the most efficient one (Figures 5a-5b and Table 1). The irradiation under the orange $\left(\lambda_{\text {exc }}=590 \mathrm{~nm}\right)$ and $\operatorname{NIR}\left(\lambda_{\text {exc }}=850 \mathrm{~nm}\right)$ rendered analogous photo-enhanced selective hydrogenation of 4-NP where the Au-ZnO nanohybrids almost doubled the $\mathrm{ZnO}$ performance in terms of rate, conversion and $k_{a p p}$ (see Figure $5 c-5 f$ and Table 1). In these cases, the surface plasmon resonance effects at the specific edges of triangles, and larger prisms and rhombohedra (Figure 3) were able to provide additional electrons participating in the reaction. The activity that Au-ZnO exhibited under orange and NIR light (see Fig. 5 and Table 1) might be attributed to the presence of larger rhombohedra and prisms structures, as mentioned before (Figure S1). This kind of shape usually shifts the plasmon absorption band to NIR wavelengths providing the possibility to perform photocatalysis in that range despite the low energy provided by such radiation. This existence of a higher amount of rhombohedral shaped particles (and other shapes) also imply the presence of more apexes that are hot spots where is well known that the SPR band is more intense. Thus, upon excitation at that wavelength, a higher electron density is generated, aiding the progress of the reaction ${ }^{[1,4,33,37,41-43]}$.

It is also worth mentioning that $\mathrm{ZnO}$ exhibited certain activity that could be solely attributed to a residual catalytic contribution observed even in the control experiments carried out in the dark (Table 1). This phenomenon though, is not completely unprecedented and has been previously reported in the literature ${ }^{[19,43-45]}$. Besides, it must pointed out the fit of the pseudo-first kinetic order was less straightforward for these latter LED experimental conditions. This might be attributed to the fact that the electrons on the gold's surface as well as the ones injected into the support are simultaneously participating in the reaction, giving distinct contributions which thus lead to a reaction that is not pseudo-first order. There are evidences of non-conventional behaviors for the reduction of p-nitrophenol with an excess of $\mathrm{NaBH}_{4}$ reported in the literature ${ }^{[46]}$, besides the standard pseudo-first order model. Finally, a recyclability experiment was performed in order to evaluate the photocorrosion of the catalyst previously described in literature ${ }^{[10,}$ ${ }^{11]}$. Figure 6 shows the results of consecutive photocatalytic cycles carried out under UV-LED irradiation for $15 \mathrm{~min}$ and replacing each cycle with fresh reactants (Figure 6a). Despite of 
using the most energetic LED as the most plausible to induce photocorrosion, no significant changes in the conversion of 4-NP were observed after those 4 consecutive runs (Figure 6a-6b). Furthermore, the morphology of the catalyst after reaction seems unaltered with the presence of the anisotropic gold still present in the sample and no evidences of damage on the $\mathrm{ZnO}$ support (Figure 6c).

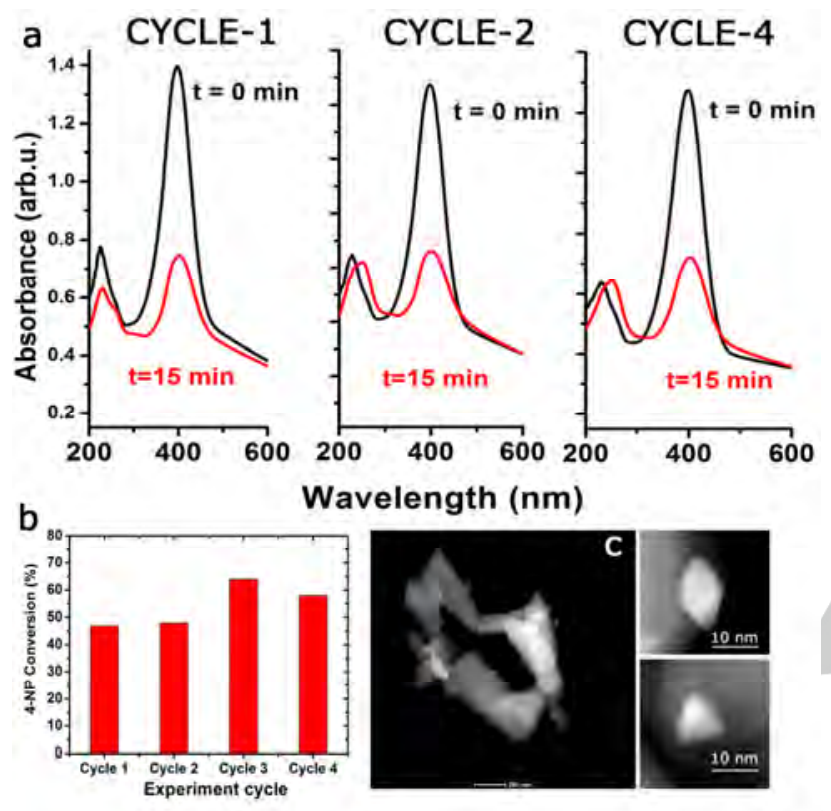

Figure 6. Recyclability of the Au-ZnO photocatalyst: a) UV-Vis spectra of 4-NP before and after irradiation with UV-LED at $365 \mathrm{~nm}$ in different and consecutive cycles with a recycled catalyst and using fresh reactants in each new cycle; b) 4-NP conversions obtained for each reaction run; c) HAADFSTEM images of the catalyst after multiple reaction cycles, including enlarged images of gold anisotropic structures.

\section{Conclusions}

The in situ deposition of anisotropic Au nanostructures onto ZnO has enabled the development of a metal-semiconductor nanohybrid with proven capacity to expand the photocatalytic response of pure ZnO beyond the UV region. ZnO itself and UV light by direct photolysis remain as the most active strategies to tackle the selective hydrogenation of p-nitrophenol. The presence of different Au metal structures has been shown more effective in the blue-emitting range at $460 \mathrm{~nm}$ with moderate response in the remaining visible-NIR ranges. A combination of surface plasmon resonance effects provided by the different edges, lengths of the different anisotropic shapes plus interband transitions in the metal-semiconductor interphases seem to be the most plausible causes for the enhanced response in the Au$\mathrm{ZnO}$ nanohybrid. The contribution of complex intermediates can not be completely ruled out. Even though, there are still better catalysts for this specific reaction, the present work has demonstrated an easy and facile synthesis approach to promote the direct formation of anisotropic gold nanostructures onto $\mathrm{ZnO}$ supports that paves the way for future photocatalytic reactions where the use of the whole solar spectrum is envisaged.

\section{Experimental Section}

\section{Chemicals}

The chemicals in this work were not purified or modified prior to their use and were purchased from Sigma-Aldrich. The gold precursor, gold (III) tetrachloroauric acid hydrate $\left(\mathrm{HAuCl}_{4} \cdot \mathrm{xH}_{2} \mathrm{O}, \geq 99.9 \%, \sim 50 \% \mathrm{Au}\right.$ basis), sodium citrate tribasic dihydrate $\left(\mathrm{HOC}(\mathrm{COONa})\left(\mathrm{CH}_{2} \mathrm{COONa}\right)_{2} \cdot 2 \mathrm{H}_{2} \mathrm{O}, \geq\right.$ $99 \%)$, sodium borohydride $\left(\mathrm{NaBH}_{4}, \geq 99.0 \%\right)$, 4-nitrophenol ( $\left.\geq 99.0 \%\right)$, and zinc oxide ( $\geq 99 \%)$.

\section{Synthesis of gold nanotriangles on different oxide supports}

The synthesis method selected was the reduction of the gold precursor, gold (III) tetrachloroauric acid $\left(\mathrm{HAuCl}_{4}\right)$ with the aid of a strong reducing agent, sodium borohydride $\left(\mathrm{NaBH}_{4}\right)$ under basic conditions. The formed particles were stabilized by the sodium citrate $\left(\mathrm{HOC}(\mathrm{COONa})\left(\mathrm{CH}_{2} \mathrm{COONa}\right)_{2}\right)$ and deposited onto the surface of $\mathrm{ZnO}$. In a typical synthesis, $1 \mathrm{~g}$ of $\mathrm{ZnO}$ was dispersed in $40 \mathrm{~mL}$ of distilled water contained in a borosilicate glass. The mixture was then adjusted to a pH of 12.5 with the aid of $\mathrm{NaOH}(1 \mathrm{M})$. In order to achieve a good suspension degree, the system was left to stir for 15 minutes. Then, 20 $\mathrm{mg}$ of the gold precursor $\left(\mathrm{HAuCl}_{4}\right)$ were added to $3 \mathrm{~mL}$ of water, which was subsequently added dropwise, to the ZnO suspension. Later, 23.5 $\mathrm{mg}$ of $\mathrm{Na}$ citrate dissolved in $2 \mathrm{~mL}$ of $\mathrm{DI}$ water was added and left stirring for 15 additional minutes to ensure a homogeneous mixing. Finally, a freshly prepared aqueous solution of $\mathrm{NaBH}_{4}$ (3.8 $\mathrm{mg}$ in $5 \mathrm{~mL}$ of DI water) was added to perform the reduction of the gold precursor during 40 minutes. After completing the reduction, the system was filtered with warm water $\sim 60{ }^{\circ} \mathrm{C}$ and left to dry overnight at the same temperature. The syntheses of the nanomaterials have been performed by the Platform of Production of Biomaterials and Nanoparticles of the NANOBIOSIS ICTS, more specifically by the Nanoparticle Synthesis Unit of the CIBER in BioEngineering, Biomaterials \& Nanomedicine (CIBER$B B N)$.

\section{Photocatalytic reaction tests}

The setup consisted of two opposite LEDs irradiators (LED emitters from Led Enging couple to a Synjet ${ }^{\circledR}$ cooling system) placed at both sides of a 
cuvette containing the reaction mixture (Figure 4). The reaction progress was monitored by acquiring absorption spectra at regular intervals of 5 minutes in the $250-500 \mathrm{~nm}$ range and measuring the UV absorption intensity at $400 \mathrm{~nm}$ (accounting for the reaction intermediate 4nitrophenolate anion). The reaction was monitored for 20 minutes (unless otherwise stated). The reaction mixture used water as solvent at a basic $\mathrm{pH}$ of $\sim 9.5$ to ensure that the 4-NP molecules were present as the 4nitrophenolate ionic form ${ }^{[33]}$. The total reaction volume within the cuvette was of $2.1 \mathrm{~mL}$, with $700 \mu \mathrm{L}$ from a stock solution of 4-NP ([4-NP] $=0.153$ $\mathrm{mM}), 700 \mu \mathrm{L}$ of a solution with fresh $\mathrm{NaBH}_{4}\left(\left[\mathrm{NaBH}_{4}\right]=15 \mathrm{mM}\right)$ and the rest was a suspension of the catalyst $(0.0075 \mathrm{mM})$. The final concentrations in the cuvette were, thus, $0.051 \mathrm{mM}$ (4-NP), $5 \mathrm{mM}$ $\left(\mathrm{NaBH}_{4}\right)$ and $0.0025 \mathrm{mM}(\mathrm{ZnO}$ or Au-ZnO). The selection of LEDs tested included wavelengths in the whole spectrum: $850 \mathrm{~nm}, 590 \mathrm{~nm}, 460 \mathrm{~nm}$ and $365 \mathrm{~nm}$. In addition, a set of control experiments in the absence of light and in the absence of catalysts were also performed for comparison and included in the same figures. The conversion is obtained following the absorbance of the sample at $400 \mathrm{~nm}$ along the reaction and applying the formula: $A_{t 0}-A_{t} / A_{t 0} \times 100$ that is subsequently converted into concentration values via interpolation of the absorbance values in a calibration curve carried out in advance. Because the concentration of $\mathrm{NaBH}_{4}$ was in great excess, it was considered as constant throughout the reaction. Therefore the hydrogenation rate was approximated to a pseudo-first kinetic order with regard to the 4-NP concentration. An apparent kinetic constant $\left(k_{\text {app }}\right)$ was determined from the plot of $\operatorname{Ln}[\mathrm{C}(t) / \mathrm{C}(0)]$ versus LED irradiation times, being $\mathrm{C}(t)$ and $\mathrm{C}(0)$, the concentration of 4-NP at different irradiation times and at $t=0 \mathrm{~min}$, respectively.

\section{Characterization techniques}

The absorption spectra were obtained with UV-Vis spectroscopy, performed in a Jasco V-670 UV-VIS-NIR Spectrophotometer: the absorption spectra of the different solid materials were acquired with an integrated sphere accessory and the reactions were followed up with the normal liquid setup at the wavelength of $400 \mathrm{~nm}$. TEM (Transmission electron microscopy) images were acquired with a FEI Tecnai T20 operated at $200 \mathrm{kV}$ and a FEI Tecnai F30 at $300 \mathrm{kV}$ at the LMA (Laboratorio de Microscopias Avanzadas). Aberration corrected scanning transmission electron microscopy images were acquired using a high angle annular dark field detector in a FEI XFEG TITAN electron microscope operated at $300 \mathrm{kV}$ equipped with a CETCOR Cs-probe corrector from CEOS Company allowing forming an electron probe of $0.08 \mathrm{~nm}$. The geometric aberrations of the probe-forming system were controlled to allow a beam convergence of 24.7 mrad half-angle to be selected. Elemental analysis was carried out with EDS (EDAX) detector which allows performing EDX experiments in scanning mode. The samples were suspended in ethanol, under sonication, and 3 drops of each sample were carefully dropcasted onto $\mathrm{Cu}$ mesh grids. The MPAES (Microwave Plasma - Atomic Emission Spectroscopy) analysis was performed with an Agilent 4100 MP-AES to quantify the gold present on the support. The samples were prepared with a previous digestion with aqua regia (1:3 nitric acid:hydrochloric acid, molar proportion) in a microwave, at $200{ }^{\circ} \mathrm{C}$ for ten minutes, to dissolve the gold. At least three independent measurements and digestions were carried out for each sample. X-ray diffraction (XRD) was performed to identify the crystalline structures, making use of an Empyrean PANalytical diffractometer. The scans were taken with $\mathrm{CuK}_{\alpha}$ radiation at intervals of $0.005^{\circ}(2 \theta)$, with collection times of 5 seconds.

\section{Acknowledgments}

The authors acknowledge the European Research Council for funding through an Advanced Grant research project (CADENCE grant number 742684). Financial support from MINECO (Spain) (ARCADIA-CTQ2016-79419-R) and the CIBER-BBN (initiative funded by the VI National R\&D\&i Plan 2008-2011, Iniciativa Ingenio 2010, Consolider Program, CIBER Actions and financed by the Instituto de Salud Carlos III with assistance from the European Regional Development Fund) is gratefully acknowledged. The synthesis of materials has been performed by the Platform of Production of Biomaterials and Nanoparticles of the NANOBIOSIS ICTS, more specifically by the Nanoparticle Synthesis Unit of the CIBER in BioEngineering, Biomaterials \& Nanomedicine (CIBER-BBN). The microscopy works have been conducted in the "Laboratorio de Microscopias Avanzadas" at "Instituto de Nanociencia de Aragon Universidad de Zaragoza. Authors acknowledge the LMA-INA for offering access to their instruments and expertise. B.B-P. acknowledges the University of Zaragoza and Fundacion Carolina for funding his MSc. studies.

Keywords: plasmonic $\cdot$ photocatalysis $\cdot$ nanotriangles $\bullet$ zinc oxide $\cdot$ LED

[1] C. P. Li, P. Wang, Y. Tian, X. L. Xu, H. Hou, M. M. Wang, G. H. Qi, Y. D. Jin, ACS Catal. 2017, 7, 5391-5398.

[2] A. Nezamzadeh-Ejhieh, S. Khorsandi, J. Ind. Eng. Chem. 2014, 20, 937-946.

[3] Y. S. Seo, E. Y. Ahn, J. Park, T. Y. Kim, J. E. Hong, K. Kim, Y. Park, Y. Park, Nanoscale Res. Lett. 2017, 12, 11.

[4] G. L. Hallett-Tapley, M. J. Silvero, C. J. Bueno-Alejo, M. GonzalezBejar, C. D. McTiernan, M. Grenier, J. C. Netto-Ferreira, J. C. Scaiano, J. Phys. Chem. C 2013, 117, 12279-12288.

[5] M. C. Ortega-Liebana, J. L. Hueso, S. Ferdousi, R. Arenal, S. Irusta, K. L. Yeung, J. Santamaria, Appl. Catal. B-Environ. 2017, 218, 68-79.

[6] M. Rohe, K. Merz, Eur. J. Inorg. Chem. 2008, 3264-3268.

[7] K. Nakata, A. Fujishima, J. Photochem. Photobiol. C-Photochem. Rev. 2012, 13, 169-189.

[8] M. Zalfani, B. van der Schueren, M. Mandouani, R. Bourguiga, W. B. Yu, M. Wu, O. Deparis, Y. Li, B. L. Su, Appl. Catal. B-Environ. 2016 199, 187-198

[9] C. J. Bueno-Alejo, J. L. Hueso, R. Mallada, I. Julian, J. Santamaria Chem. Eng. J. 2019, 358, 1363-1370. 
[10] W. Xie, Y. Z. Li, W. Sun, J. C. Huang, H. Xie, X. J. Zhao, J. Photochem. Photobiol. A-Chem. 2010, 216, 149-155.

[11] Y. Z. Li, W. Xie, X. L. Hu, G. F. Shen, X. Zhou, Y. Xiang, X. J. Zhao, P. F. Fang, Langmuir 2010, 26, 591-597.

[12] Y. Z. Li, X. Zhou, X. L. Hu, X. J. Zhao, P. F. Fang, J. Phys. Chem. C 2009, 113, 16188-16192.

[13] Q. C. Ma, X. N. Peng, M. L. Zhu, X. N. Wang, Y. Y. Wang, Y. Gao, H. Wang, J. Phys. D-Appl. Phys. 2019, 52.

[14] P. She, K. L. Xu, Y. X. Shang, Q. R. He, S. Zeng, S. Y. Yin, G. L. Lu, S. Liang, H. Sun, Z. N. Liu, New J. Chem. 2018, 42, 3315-3321.

[15] T. Ngwenya, I. Nongwe, L. L. Jewell, Gold Bull. 2018, 51, 153-162.

[16] L. Ma, S. J. Ding, Mater. Lett. 2018, 217, 255-258.

[17] S. Kim, Y. Yu, S. Y. Jeong, M. G. Lee, H. W. Jeong, Y. M. Kwon, J. M. Baik, H. Park, H. W. Jang, S. Lee, Catal. Sci. Technol. 2018, 8, 37593766.

[18] L. C. Du, W. D. Xi, J. B. Zhang, H. Matsuzaki, A. Furube, Chem. Phys. Lett. 2018, 701, 126-130.

[19] A. Sinhamahapatra, A. K. Giri, P. Pal, S. K. Pahari, H. C. Bajaj, A. B. Panda, J. Mater. Chem. 2012, 22, 17227-17235.

[20] H. F. Cheng, K. Fuku, Y. Kuwahara, K. Mori, H. Yamashita, J. Mater. Chem. A 2015, 3, 5244-5258.

[21] S. Parola, B. Julian-Lopez, L. D. Carlos, C. Sanchez, Adv. Funct. Mater. 2016, 26, 6506-6544.

[22] T. Barakat, J. C. Rooke, E. Genty, R. Cousin, S. Siffert, B. L. Su, Energy Environ. Sci. 2013, 6, 371-391.

[23] E. Petryayeva, U. J. Krull, Anal. Chim. Acta 2011, 706, 8-24.

[24] L. Gomez, J. L. Hueso, M. C. Ortega-Liebana, J. Santamaria, S. B. Cronin, Catal. Commun. 2014, 56, 115-118.

[25] M. C. Ortega-Liebana, J. L. Hueso, R. Arenal, J. Santamaria, Nanoscale 2017, 9, 1787-1792.

[26] M. Zieba, J. L. Hueso, M. Arruebo, G. Martinez, J. Santamaria, New J. Chem. 2014, 38, 2037-2042.

[27] M. J. Kale, T. Avanesian, P. Christopher, ACS Catal. 2014, 4, 116-128.

[28] C. L. Wang, D. Astruc, Chem. Soc. Rev. 2014, 43, 7188-7216.

[29] X. M. Zhang, Y. L. Chen, R. S. Liu, D. P. Tsai, Rep. Prog. Phys. 2013, 76.

[30] L. M. Molina, B. Hammer, Phys. Rev. B 2004, 69, 22.

[31] J. Crespo, A. Ibarra, J. M. Lopez-de-Luzuriaga, M. Monge, M. E. Olmos, Eur. J. Inorg. Chem. 2014, 2014, 2383-2388.

[32] I. Pastoriza-Santos, R. A. Alvarez-Puebla, L. M. Liz-Marzan, Eur. J. Inorg. Chem. 2010, 4288-4297.

[33] J. Graus, C. J. Bueno-Alejo, J. L. Hueso, Catalysts 2018, 8, 16.

[34] L. Chen, F. Ji, Y. Xu, L. He, Y. F. Mi, F. Bao, B. Q. Sun, X. H. Zhang, Q. Zhang, Nano Lett. 2014, 14, 7201-7206.

[35] R. B. Jiang, B. X. Li, C. H. Fang, J. F. Wang, Adv. Mater. 2014, 26 5274-5309.

[36] M. Hajfathalian, K. D. Gilroy, A. Yaghoubzade, A. Sundar, T. Tan, R. A. Hughes, S. Neretina, J. Phys. Chem. C 2015, 119, 17308-17315.

[37] K. Kuroda, T. Ishida, M. Haruta, J. Mol. Catal. A-Chem. 2009, 298, 7-11.

[38] N. Miguel-Sancho, G. Martinez, V. Sebastian, A. Malumbres, I. Florea, R. Arenal, M. C. Ortega-Liebana, J. L. Hueso, J. Santamaria, ACS Appl. Mater. Interfaces 2017, 9, 41529-41536.

[39] Z. D. Pozun, S. E. Rodenbusch, E. Keller, K. Tran, W. J. Tang, K. J. Stevenson, G. Henkelman, J. Phys. Chem. C 2013, 117, 7598-7604.

[40] S. Sarina, E. R. Waclawik, H. Y. Zhu, Green Chem. 2013, 15, 1814 1833.

[41] A. O. Govorov, H. Zhang, H. V. Demir, Y. K. Gun'ko, Nano Today 2014 9, 85-101.

[42] B. Joshi, P. Saxena, N. Khera, Optical properties of Zinc oxide (ZnO) thin films for applications in optical devices: MATLAB Simulation, leee, New York, 2016.

[43] M. M. Khan, S. F. Adil, A. Al-Mayouf, J. Saudi Chem. Soc. 2015, 19, 462-464.

[44] M. Sabbaghan, A. Ghalaei, J. Mol. Liq. 2014, 193, 116-122.
[45] M. Hosseini-Sarvari, M. Tavakolian, Appl. Catal. A-Gen. 2012, 441, 6571.

[46] M. L. Li, G. F. Chen, Nanoscale 2013, 5, 11919-11927. 


\section{Entry for the Table of Contents}

\section{FULL PAPER}

Gold in shape!: This work reports on the direct reduction and assembly of plasmonic gold nanostructures with different anisotropic shapes onto ZnO particles. The metalsemiconductor assembly expands the photocatalytic response of $\mathrm{ZnO}$ beyond its expected UV window in the LED-driven selective reduction of p-nitrophenol.

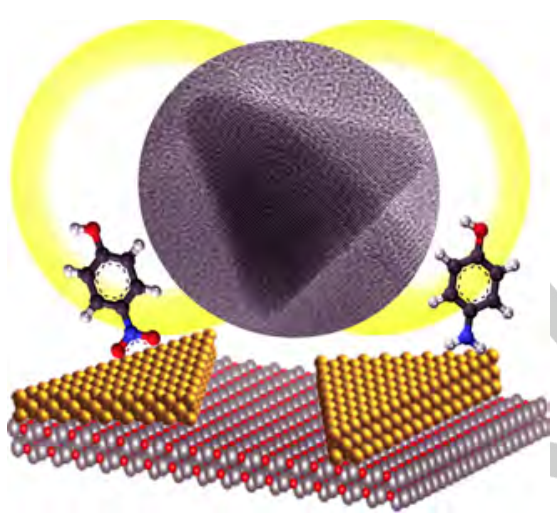

Plasmonic Photocatalysts

B. Bottega-Pergher, J. Graus, C.J. Bueno-Alejo*, Dr. J.L. Hueso*

Page No. - Page No.

Triangular and prism-shaped goldzinc oxide plasmonic nanostructures: in situ reduction, assembly and full-range photocatalytic performance 